\title{
Effect of the establishment of dominance relationships on cortisol and other metabolic parameters in Nile tilapia (Oreochromis niloticus)
}

S.A. Corrêa ${ }^{1}$, M.O. Fernandes ${ }^{2}$, K.K. Iseki ${ }^{3}$ and J.A. Negrão ${ }^{1}$

\author{
${ }^{1}$ Departamento de Ciências Básicas, Faculdade de Zootecnia e Engenharia \\ de Alimentos, Universidade de São Paulo, Pirassununga, SP, Brasil \\ ${ }^{2}$ Departamento de Fisiologia Animal, Universidade Federal do Paraná, \\ Curitiba, PR, Brasil \\ ${ }^{3}$ Departamento de Fisiologia, Instituto de Biologia, Universidade de São Paulo, \\ São Paulo, SP, Brasil
}

Correspondence

S.A. Corrêa

Departamento de Ciências Básicas

Faculdade de Zootecnia e

Engenharia de Alimentos, USP

13630-000 Pirassununga, SP

Brasil

E-mail: sandro_a_c@yahoo.com.br

Research supported by FAPESP and CAPES.

Received January 22, 2003 Accepted August 20, 2003

\begin{abstract}
The objective of the present study was to investigate the influence of the establishment of dominance relationships and social stress on plasma cortisol and metabolite levels in Nile tilapia (Oreochromis niloticus). During the 30-day experiment, the fish weighing $236 \pm 29 \mathrm{~g}$ were kept in individual aquaria, except for two pairings lasting $6 \mathrm{~h}$ each. Blood samples were taken from the animals before and after pairing. Display, approach, attack, rebuff, chase flight, and coloration were carried out on days 16 and 30. Activities and behaviors characteristic of the establishment of dominance relationships were described. It was possible to classify all experimental fish $(\mathrm{N}=30)$ as dominant or subordinate. No differences were detected between dominant $(\mathrm{N}=15)$ and subordinate $(\mathrm{N}=15)$ fish during isolation or after pairing in cortisol (isolated: $5.76 \pm 0.98$ vs $5.42 \pm 0.63$; paired: 10.94 \pm 1.62 vs $11.21 \pm 2.45 \mu \mathrm{g} / \mathrm{dl}$ ), glucose (isolated: $60.02 \pm 4.9$ vs 67.85 \pm 16.16 ; paired: $110.44 \pm 15.72$ vs $136.26 \pm 22.46 \mathrm{mg} / \mathrm{dl}$ ), triglyceride (isolated: $167.87 \pm 5.06 v s 185.68 \pm 7.24$; paired: $210.85 \pm 13.40 v s$ $221.82 \pm 12.70 \mathrm{mg} / \mathrm{dl}$ ) or total protein levels (isolated: $7.01 \pm 0.42 \mathrm{vs}$ $6.69 \pm 0.59$; paired: $9.21 \pm 0.62$ vs $9.51 \pm 0.66 \mathrm{~g} / \mathrm{dl})$. However, when isolated $(\mathrm{N}=30)$ and paired $(\mathrm{N}=30)$ tilapia were compared, there were significant differences in cortisol and metabolite levels. The similar response presented by dominant and subordinate tilapia indicates that establishment of dominance relationships was a stressor for both groups.
\end{abstract}

Key words

- Tilapia

- Social stress

- Social relationships

- Agonistic behaviors

- Cortisol

- Dominance

\section{Introduction}

A phenomenon commonly described in territorial species such as Nile tilapia (Oreochromis niloticus) is social stress (1-3). Sometimes, social interactions stimulate an in- crease in cortisol levels (3-5). In general, cortisol levels are of considerable value in the assessment of stress because cortisol is involved in metabolic adjustments and energy mobilization by acting on carbohydrate, protein and lipid metabolism $(2,6,7)$. 
On a long-term basis, an increase in cortisol concentration has been directly associated with a decrease in growth rate in fish (6). Barton and Iwama (8) have also observed that exogenous cortisol administration induced a remarkable decrease in the growth rate of rainbow trout (Oncorhynchus mikiss). Moreover, subordinate fish showed a lower growth rate than dominant animals $(2,9,10)$.

Some investigators have proposed that physiological responses to social stress are more marked in subordinate animals due to a larger energy expense during agonistic confrontations $(5,11)$. Others have suggested that triglycerides are also mobilized in response to stress $(12,13)$. An increase in plasma glucose levels has also been observed in fish submitted to acute and chronic stress $(14,15)$. It is likely that the mass loss in animals submitted to chronic stress is the result of protein mobilization due to increased cortisol levels which enhance the availability of energy $(16,17)$. On the other hand, Stott (18) suggested that cortisol levels can only be related to stress during and immediately after submission to stressors.

However, it is not clear whether agonistic confrontation can cause metabolic and hormonal changes. It is well known that tilapia of similar age and genetic background submitted to similar environments, nutrition and management can have different growth levels. This heterogeneity is due in part to the fact that dominant fish have priority of access to food compared to subordinate fish. However, before studying the effect of social relationships on growth it is necessary to determine how the establishment of dominance relationships can cause metabolic and hormonal adjustments. On this basis, the objective of the present study was to investigate the influence of the establishment of dominance relationships (and the social stress involved) on cortisol, glucose, triglyceride and total protein levels in dominant and subordinate Nile tilapia.

\section{Material and Methods}

Pellet ration for fish (Socil, Descalvado, SP, Brazil) was offered to the tilapia throughout the experiment at $3 \%$ of body mass. A filtering system with constant aeration was installed in the aquaria, and each aquarium was cleaned weekly. Water quality (dissolved oxygen, ammonia, nitrate, nitrite and $\mathrm{pH}$ ) was monitored weekly. Ambient temperature was maintained with an air conditioning system and water temperature was kept at 26 $\pm 7^{\circ} \mathrm{C}$ throughout the experiment. The photoperiod used was a 12-h light-dark cycle, with lights on at 6:00 am.

\section{Pre-experimental procedure}

Thirty male Nile tilapia weighing $236 \pm$ $29 \mathrm{~g}$ were identified individually with plastic tags on the dorsal fin and transferred to 30 different glass aquaria (separated to prevent visual contact). Each aquarium ( 70 × 30 × 30 $\mathrm{cm})$ had a capacity of 63 liters. The fish were weighed and measured weekly and food intake was quantified at 5-day intervals during an adaptation period of 15 days. At the end of this pre-experimental phase, all fish had maintained or gained mass and therefore were considered to have adapted to the experimental conditions.

\section{Experimental procedure}

During the experimental period of 30 days, each tilapia remained in an individual aquarium (no visual contact, free of social stress), except during the period of pairing (social stress imposed). Each pairing took place in a neutral aquarium to avoid a "previous residence" effect. Fifteen pairs of experimental fish of similar size and body mass were transferred to this neutral aquarium for $6 \mathrm{~h}$ on days 16 and 30 . The same pairs of individual fish were tested on the two experimental days.

On days 16 and 30, each fish was meas- 
ured and weighed, and a blood sample was removed by caudal vein puncture for individual measurements before pairing. The fish were then carefully removed from their individual aquaria and paired for $6 \mathrm{~h}$ (social stress imposed). At the end of pairing, all fish were submitted to a second blood sampling for measurements after exposure to social stress (paired measures). The capture, anesthetic procedure, measurement, weighing and blood sampling (approximately $1 \mathrm{ml}$ of blood) lasted a total of $2 \mathrm{~min}$, based on the procedure reported by Auperin et al. (19).

\section{Dominance relationships}

Behavioral observations were conducted on days 16 and 30 during the 6-h period of pairing. During this monitoring period we noted the following behaviors: display, approach, attack, rebuff, chase and flight (see Results for descriptions). Simultaneously, we noted the position (upper, intermediate or lower, and left or right) of each fish in the aquarium. These data were used to determine the social rank (dominant or subordinate) of each fish in the pairing. Thus, 15 fish were classified as dominant, and the other 15 fish were classified as subordinate. It is important to note that the dominance relationships remained the same in the second pairing.

All pairing experiments were completely recorded on videotape. Five minutes at the beginning and at the end of the video were then observed to determine the pigmentation of each fish (silver with sharp black stripes or dark gray without black stripes) and the frequency of agonistic behaviors (total number of attacks plus rebuffs) initiated by each fish.

\section{Hormonal and metabolic analysis}

Blood samples were collected into chilled tubes and immediately centrifuged at $1500 \mathrm{~g}$ for $15 \mathrm{~min}$ at $4^{\circ} \mathrm{C}$, and plasma was stored at $-20^{\circ} \mathrm{C}$ until analysis. Commercial enzymatic kits were used (Weiner Laboratory, Rosario, Argentina) to determine plasma levels of glucose, triglycerides and total proteins. After validation, plasma cortisol levels were determined by enzyme immunoassay (EIA), with an interassay and intra-assay coefficient of variation of 6.1 and $10.52 \%$, respectively, using commercial kits (Diagnostic System Laboratories, Inc., Webster, TX, USA).

\section{Statistical analysis}

Statistical comparison of the means for all parameters were carried out using GraphPad (20) and the Kruskal-Wallis test, with the level of significance set at $\mathrm{P}<0.05$. Correlations between the parameters analyzed were determined by the Pearson correlation test using the SAS System for Windows, version 6.12 (21). All data are reported as means \pm SEM.

\section{Results}

At the beginning of pairing, both fish swam and displayed a silver coloration with sharp black stripes. They then swam closer to one another, approached, attacked (in general with tail beating), and fled. A few minutes later, the paired fish became more aggressive and attacked or reacted with a vigorous rebuff, such as mouth fighting and ramming. During this period of intensive interaction, both fish presented a light coloration, without black stripes. Sometimes, one of the fish chased and bit the flanks of the other fish that was fleeing. However, challenged fish mostly rebuffed attacks and another confrontation began. As shown in Figure 1, at the beginning of pairing there was no significant difference in the number of agonistic behaviors initiated by dominant or subordinate fish. Confrontations were rare after $2.5 \mathrm{~h}$.

At the end of pairing, we could identify the 
Figure 1. Number of agonistic behaviors (attacks plus rebuffs) initiated during the first (1) and last (2) 5 min of pairing of dominant (Dom) and subordinate (Sub) Nile tilapia. Data are reported as means \pm SEM for 15 fish. Data for days 16 and 30 were combined. Significantly different $(P<0.05)$ means are indicated by different letters (KruskalWallis test).

Figure 2. Plasma cortisol (A), glucose $(\mathrm{B})$, triglycerides $(\mathrm{C})$ and total protein (D) observed in dominant (Dom) and subordinate (Sub) Nile tilapia while isolated (Isol) and after pairing (Pair). Data are reported as means \pm SEM for 15 fish. Significantly different means $(P<0.05)$ are indicated by different letters (Tukey test).

Figure 3. Plasma cortisol (A), glucose $(B)$, triglyceride $(C)$ and total protein (D) levels observed in Nile tilapia while isolated and after pairing. Data are reported as means \pm SEM for 30 fish. Significantly different means $(P<$ $0.05)$ are indicated by different letters (Tukey test).
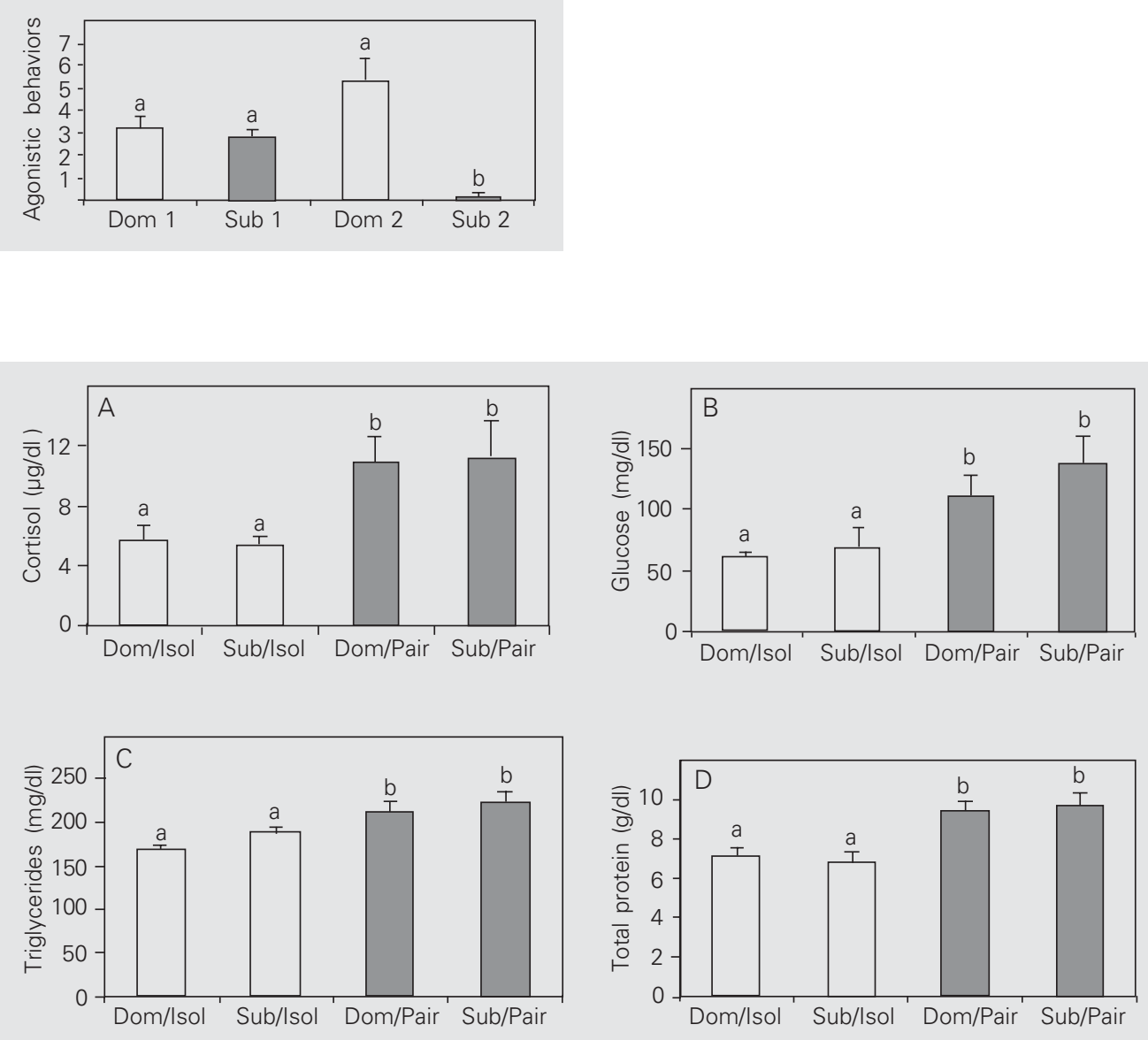
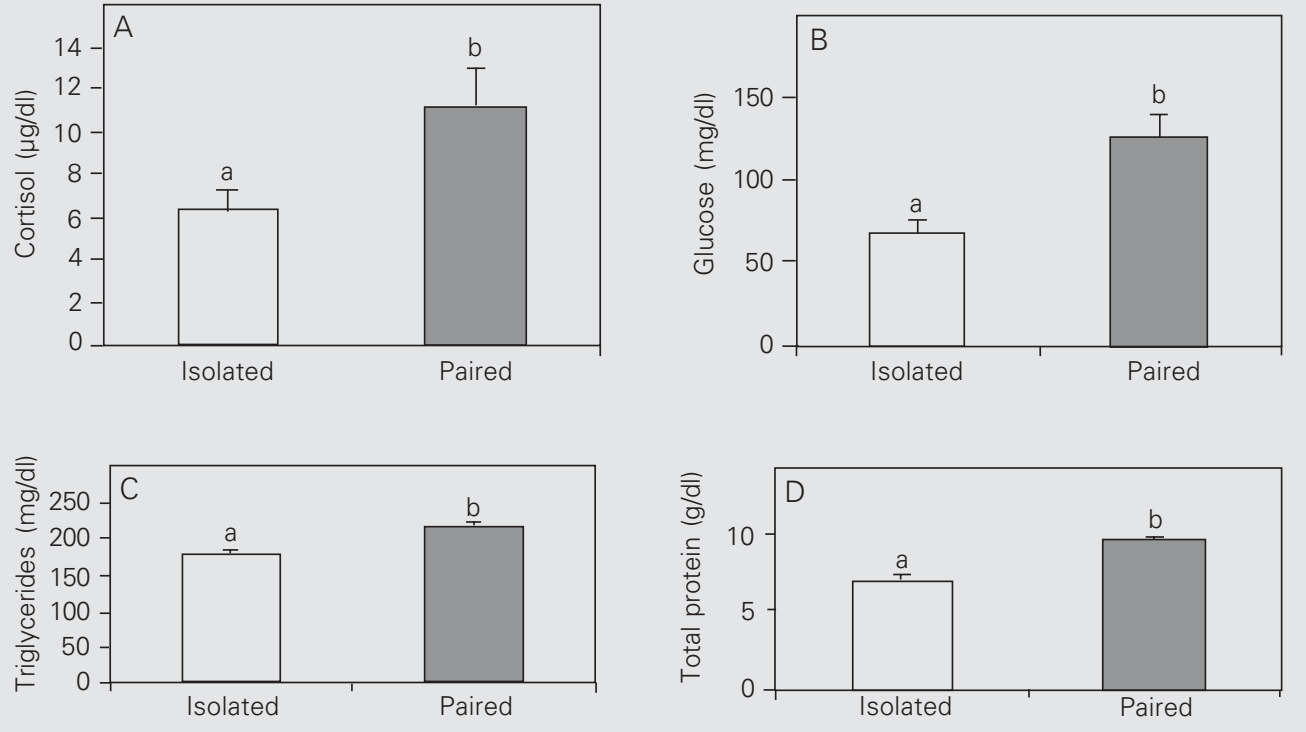
dominant fish as the one having a silver coloration with sharp black stripes, swimming normally, and that chased and occasionally attacked the other fish when approached. At the same time, subordinate fish had a dark gray coloration without stripes and did not rebuff the aggressive behaviors of the other fish. Furthermore, subordinate fish remained in the section of the aquarium opposite to the dominant fish and avoided the dominant fish. During this phase, subordinate fish rarely attacked dominant fish and there was a significant increase in the number of agonistic behaviors initiated by the dominant fish compared to the subordinate fish (Figure 1). In general, subordinate fish swam slowly and showed a higher number of injures (wounds with scales missing) than dominant fish.

Glucose, triglyceride, total protein and plasma cortisol levels were not significantly different between fish classified as dominant and subordinate, either during isolation or after pairing (Figure 2). However, glucose, triglyceride, total protein and plasma cortisol levels measured during isolation were lower than those measured after pairing for the fish as a whole (see Figure 3).

There were no differences in body mass, size or feed intake between dominant and subordinate fish during the experiment. Compared to the beginning of the experiment, however, there were numerical increases in body mass (from $236.10 \pm 5.60$ to $243.57 \pm$ $5.80 \mathrm{~g}$ ), length (from $19.10 \pm 0.22$ to $19.30 \pm$ $0.20 \mathrm{~cm}$ ) and feed intake (from $7.50 \pm 0.25$ to $9.45 \pm 0.50 \mathrm{~g} /$ day) at the end of the experimental period.

There were positive correlations between levels measured during isolation and after pairing for glucose $(\mathrm{r}=0.29, \mathrm{P}<0.05)$ and triglyceride levels $(r=0.45, P<0.05)$, but not for cortisol or total protein levels. At the same time, there was a positive correlation between glucose and cortisol levels $(r=0.65$, $\mathrm{P}<0.05)$. However, there was a negative correlation between glucose and triglyceride levels $(\mathrm{r}=-0.47, \mathrm{P}<0.05)$. Cortisol and triglyceride levels were not correlated and total protein levels were not correlated with any of the other three parameters.

\section{Discussion}

Activities and behaviors characteristic of the establishment of dominance relationships were observed during all pairings and it was possible to classify all experimental fish as dominant or subordinate because dominance relationships had been clearly established by the end of pairing. This classical response to acute stress has been previously described in tilapia by others $(1,3,5)$. Our results also agree with those reported by Peters et al. (14) and Domingues (22) who showed that, although subordinate fish suffer a greater number of attacks than dominant fish, the dominance status is not a good indicator of the stress level.

Nevertheless, in the present study, there were no differences in cortisol, glucose, triglyceride or total protein levels between dominant and subordinate fish. These results suggest that social interactions during the establishment of the dominance relationship are an important stress factor for Nile tilapia and cause similar increases in cortisol and metabolic parameters in both dominant and subordinate fish. After the establishment of dominance relationships, the dominant animal normally replaces attack behaviors with threats, and the subordinate animal replaces rebuffs with flight (2). In the present study, however, no threats were observed.

Other investigators (5) have proposed that physiological and metabolic responses are more marked in subordinate than in dominant Nile tilapia. It is important to note that Fernandes (5) worked with fish maintained in experimental groups for several days. It is possible that the marked responses of subordinate fish were influenced by both social interactions (acute stress) and the length of grouping time (chronic stress). Furthermore, during lengthy grouping of many fish, ap- 
proaches and threats lead to attacks, rebuffs and fights (2).

In the present study, experimental fish were kept isolated, except during pairing when two fish were transferred to a neutral aquarium. In this case, imposed acute stress can be hypothesized to be more intense than in a group, because the agonistic behaviors, mainly from dominants, were focused on a single animal. Consequently, we observed a clearly significant difference in cortisol levels between isolated and paired tilapia. This has been previously described in tilapia submitted to different stressful situations $(1,3)$. In contrast, Ejike and Schreck (4) observed lower glycogen levels and similar cortisol levels when comparing dominant and solitary salmon. Thus, these investigators suggested that complete isolation is not a healthy situation. However, our results did not confirm theirs because the same tilapia had lower levels of cortisol, glucose, triglyceride and total protein when isolated than when paired, suggesting that acute stress caused a mobilization of extra energy.

As observed in the present study, work carried out with other species of fish has demonstrated that different kinds of stress cause an increase in glucose levels $(2,15,23)$. These studies also reported that high cortisol levels were positively correlated with high glucose levels. For these reasons, it is possible to confirm that stress caused an additional mobilization of glucose. At the same time, establishment of dominance relation- ships caused an increase in triglyceride levels in our study. This supports other studies showing that high cortisol and catecholamine levels cause an increase in lipase activity which promotes the breakdown of triglycerides in fat cells and consequently increases triglyceride levels in plasma $(12,13)$.

In the present study, the establishment of dominance relationships also caused a mobilization of protein as a source of energy. During the increase in energy demand provoked by stress, increased cortisol levels promote the mobilization of muscular protein in trout $(2,16,17)$. Some investigators have not observed a significant increase in total protein levels in fish submitted to social stress $(5,14)$. It is important to note that the mobilization of protein as an energy source has been observed in animals submitted to chronic stress $(7,24)$. In the chronic case, the increase in plasma cortisol concentrations is directly related to a decrease in growth rate (6). However, our data on food intake, body mass and length were not affected by the imposed acute stress, probably because the duration of pairing was not sufficiently long to affect fish development.

During pairing, the intense agonistic interactions caused a significant increase in the plasma levels of cortisol and the metabolites analyzed. The similarity of response shown by dominant and subordinate animals indicates that the establishment of dominance relationships was a stressor for both groups.

\section{References}

1. Faisal M \& Chiappelli $F$ (1989). Role of endogenous opioids in modulating some immune functions in hybrid tilapia. Journal of Aquatic Animal Health, 1: 301-306.

2. Volpato GL \& Fernandes MO (1994). Social control growth in fish. Brazilian Journal of Medical and Biological Research, 27: 797-810.

3. Barcellos LJG, Nocolaiewsky S, Souza SMG \& Lulhier F (1999). The effect of stocking density and social interactions on acute stress response in Nile tilapia (Oreochromis niloticus) fingerlings. Aquaculture Research, 30: 887-892.

4. Ejike C \& Schreck CB (1980). Stress and social hierarchy rank in coho salmon. Transactions of the American Fisheries Society, 109: 423-426.

5. Fernandes MO (1997). Estresse social, metabolismo e crescimento em peixes. Doctoral thesis, Universidade Estadual Paulista, Botucatu, SP, Brazil.

6. Pickering AD (1993). Growth and stress in fish production. Aquaculture, 111: 51-63.

7. Wendelaar Bonga SE (1997). The stress response in fish. Physiological Reviews, 77: 591-625.

8. Barton BA \& Iwama GK (1991). Physiological changes in fish from 
stress in aquaculture with emphasis on the response and effects of corticosteroids. Annual Review of Fish Diseases, 10: 3-26.

9. Jobling $\mathrm{M}$ (1985). Physiological and social constraints on growth of fish with special reference to Arctic charr (Salvelinus alpinus). Aquaculture, 44: 83-90.

10. Koebele BP (1985). Growth and the size hierarchy effect: an experimental assessment of three proposed mechanisms; activity differences, disproportional food acquisition, physiological stress. Environmental Biology of Fishes, 12: 181-188.

11. Zayan R (1991). The specificity of social stress. Behavioural Processes, 25: 91.

12. McDonald DG \& Milligan CL (1992). Chemical properties of the blood. In: Hoar WS, Randall DJ \& Farrel AP (Editors), Fish Physiology. Vol. XII. Part B, The Cardiovascular System. Academic Press, San Diego, CA, USA, 55-133.

13. Boeuf $G$ (1993). Salmonid smolting: A pre-adaptation to the oceanic environment. In: Cliff J \& Jensen FB (Editors), Fish Ecophysiology. Chapman and Hall, London, UK, 105-135.

14. Peters G, Delventhal H \& Klinger $H$ (1980). Physiological and morphological effects of social stress in the eel (Anguila anguila L.) Archiv für Fischereiwissenschaft, 30: 157-180.

15. Kubokawa K, Watanabe T, Yoshioka M \& Iwata M (1999). Effects of acute stress on plasma cortisol, sex steroid hormone and glucose levels in male and female sockeye salmon during the breeding season. Aquaculture, 172: 335-349.
16. Vijayan MM, Ballantyne JS \& Leatherland JF (1992). Cortisol-induced changes in some aspects of the intermediary metabolism of Salvelinus fontinalis. General and Comparative Endocrinology, 82: 476-486.

17. Sumpter JP (1992). Control of growth of rainbow trout (Oncorhynchus mikiss). Aquaculture, 92: 299-320.

18. Stott GH (1981). What is animal stress and how is it measured? Journal of Animal Science, 52: 150-153.

19. Auperin B, Baroiller JE, Ricordel MJ, Fostier A \& Prunet P (1997). Effect of confinement stress on circulating levels of growth hormone and two prolactins in freshwater-adapted tilapia (Oreochromis niloticus). General and Comparative Endocrinology, 108: 35-44.

20. Prism (1999). GraphPad Software Inc. (Version 3.0). San Diego, CA, USA.

21. SAS (1996). User's Guide (Release 6.12). SAS Institute Inc., Cary, NC, USA.

22. Domingues CMPM (1990). Efeito do tipo de confronto no metabolismo de alevinos de tilápia-do-Nilo (Oreochromis niloticus). Bachelor thesis, Instituto de Biociências, Universidade Estadual Paulista, Botucatu, SP, Brazil.

23. Leach JL \& Taylor MH (1981). The effects of cortisol treatment on carbohydrate and protein metabolism in Fundulus heteroclitus. General and Comparative Endocrinology, 42: 76-83.

24. Iwama GK (1997). Stress in fish. Annals of the New York Academy of Sciences, 851: 304-310. 